\title{
Elastic and plastic soil deformation and its influence on emission of greenhouse gases
}

\author{
Christoph Haas $^{1 *}$, Dörthe Holthusen ${ }^{1}$, Anneka Mordhorst ${ }^{1}$, Jerzy Lipiec ${ }^{2}$, and Rainer Horn ${ }^{1}$ \\ ${ }^{1}$ Institute for Plant Nutrition and Soil Science, CAU Kiel, Hermann-Rodewald-Str. 2, 24118 Kiel, Germany \\ ${ }^{2}$ Institute of Agrophysics, Polish Academy of Sciences, P.O. Box 201, 20-290 Lublin, Poland
}

Received January 19, 2016; accepted April 8, 2016

\begin{abstract}
A b s t r a c t. Soil management alters physical, chemical and biological soil properties. Stress application affects microbiological activity and habitats for microorganisms in the root zone and causes soil degradation. We hypothesized that stress application results in altered greenhouse gas emissions if soil strength is exceeded. In the experiments, soil management dependent greenhouse gas emissions of intact soil cores (no, reduced, conventional tillages) were determined using two experimental setups; $\mathrm{CO}_{2}$ emissions were determined with: a dynamic measurement system, and a static chamber method before and after a vertical soil stress had been applied. For the latter $\mathrm{CH}_{4}$ and $\mathrm{N}_{2} \mathrm{O}$ emissions were analyzed additionally. Stress dependent effects can be summed as follows: In the elastic deformation range microbiological activity increased in conventional tillage soil and decreased in reduced tillage and no tillage. Beyond the precompression stress a release of formerly protected soil organic carbon and an almost total loss of $\mathrm{CH}_{4}$ oxidizability occurred. Only swelling and shrinkage of no tillage and reduced tillage regenerated their microhabitat function. Thus, the direct link between soil strength and microbial activity can be applied as a marker for soil rigidity and the transition to new disequilibria concerning microbial activity and composition.
\end{abstract}

$\mathrm{K}$ e y w o r d s: biological activity, strength, compaction, respiration, gas emission

\section{INTRODUCTION}

Soil organic carbon is an important factor for soil fertility, which can be explained by the strengthening of existing aggregates (Wiesmeier et al., 2012) and positive effects on water, nutrient, heat and gas fluxes. Furthermore, due to microbiological decomposition, soil organic carbon is a source of greenhouse gases both under aerobic and anaerobic conditions. Medium-sized pores have a microhabitat function for soil microorganisms because their

\footnotetext{
*Corresponding author e-mail: c.haas@soils.uni-kiel.de
}

size is suitable for bacteria and fungi. In well-aggregated soils the aerobic microbial respiration is the main source of carbon dioxide $\left(\mathrm{CO}_{2}\right)$ emissions (Zibilske, 1994) while anaerobic soils are also considered as sources for methane $\left(\mathrm{CH}_{4}\right)$ emission (Mer and Roger, 2001). It is well known that aerated soils play an important role in the world-wide $\mathrm{CH}_{4}$ consumption. Up to $15 \%$ of the annual $\mathrm{CH}_{4}$ consumption is attributed to aerobic $\mathrm{CH}_{4}$ oxidation by soil-microbes (Powlson et al., 1997).

The ability of a soil microbial community to oxidize methane depends on various chemical parameters (Mer and Roger, 2001) including the carbon dioxide concentration (Acha et al., 2002) and therefore on the biological activity of aerobic organisms. In structured soils hot spots of microbial activity coincide with the pore geometry and actual water saturation and can therefore vary within small distances. While high $\mathrm{O}_{2}$ concentrations can be found within inter-aggregate pores and in the outer layers of aggregates (Horn, 2004; Horn and Smucker, 2005), anaerobic conditions can be found in the inner layers of larger aggregates (Horn et al., 1994). Aerobic sites presume no restrictions of the bulk soil gas diffusion coefficient due to high pore connectivity, low tortuosity, or a low degree of water saturation. Methane production (methanogenesis) on the other side requires anaerobic conditions and successive actions of four types of microorganisms that degrade complex molecules into simpler compounds (Mer and Roger, 2001). The overall net reaction is (Mer and Roger, 2001):

$$
\mathrm{C}_{6} \mathrm{H}_{12} \mathrm{O}_{6} \rightarrow 3 \mathrm{CO}_{2}+3 \mathrm{CH}_{4},
$$

and shows that the production of methane and carbon dioxide is equimolar.

(C) 2016 Institute of Agrophysics, Polish Academy of Sciences 
Another greenhouse gas emitted by agricultural soils is nitrous oxide $\left(\mathrm{N}_{2} \mathrm{O}\right)$. In anaerobic soils nitrate $\left(\mathrm{NO}_{3}^{-}\right)$is used as an electron acceptor which leads to the stepwise reduction of $\mathrm{NO}_{3}^{-}$until $\mathrm{N}_{2} \mathrm{O}$ and finally $\mathrm{N}_{2}$ formation occurs. One major reason for large emissions of $\mathrm{N}_{2} \mathrm{O}$ by agricultural soils is the application of nitrogen fertilizers (Wrage et al., 2001) or poor aeration caused by a high degree of water saturation (Linn and Doran, 1984). In addition to the formation of $\mathrm{N}_{2} \mathrm{O}$ under anaerobic conditions up to $30 \%$ of the emitted $\mathrm{N}_{2} \mathrm{O}$ originates from aerobic nitrification (Wrage, 2001).

Soil microbial communities interact with each other and with soil parameters like soil aeration and the amount of medium-sized pores. Generally, there are two kinds of soil deformation:

- elastic deformation (the precompression stress value and therewith the internal soil rigidity is not exceeded),

- plastic deformation (exceeding the precompression stress leads to soil degradation caused by aggregate failure and an irreversible loss of pore volumes and functions) (Horn and Fleige, 2003).

Consequently, soil specific reactions concerning the greenhouse gas emissions can be expected if compacting forces influence this parameters, hence a management specific reaction can be anticipated. To what extent the latter will occur is uncertain but greater knowledge of this topic will be necessary for a better understanding of recent carbon mineralization processes and greenhouse gas emissions. This paper reports an investigation of the influence of elastic and plastic deformation by mechanical loading of aggregated soils on greenhouse gas $\left(\mathrm{CO}_{2}, \mathrm{CH}_{4}, \mathrm{~N}_{2} \mathrm{O}\right)$ emissions, providing evidence of the link between the mechanical and biological properties of soil. We hypothesized that, if mechanical loading exceeds soil strength, this stress application results in altered gas emissions due to changes in soil pore functions. A linkage between mechanical and biological soil properties is helpful to define the linkage between mechanical and biological processes in soils and will have a close link to better understand carbon mineralization processes and greenhouse gas emissions.

\section{MATERIALS AND METHODS}

The soil cores were extracted in February 2013 from a Calcic Chernozem (WRB, 2006) derived from loess (80, 700 and $220 \mathrm{~g} \mathrm{~kg}^{-1}$ sand, silt, and clay, respectively) in Bernburg, Germany. Samples were taken from two depths (topsoil $=10 \mathrm{~cm}$ and subsoil $=40 \mathrm{~cm}$ ) of three different tillage systems: no tillage (NT), reduced tillage (RT) and conventional tillage (CT), under winter wheat (Triticum aestivum). The NT and RT treatments had not been tilled since 1996. In the RT field residues were incorporated into the upper 10-12 cm of soil by a disc harrow. The CT site was plowed down to $30 \mathrm{~cm}$ depth. Soil samples were stored in darkness at $4^{\circ} \mathrm{C}$. In total 24 soil cores $(\mathrm{h}=6 \mathrm{~cm}, \mathrm{r}=5 \mathrm{~cm}$, $\mathrm{n}=4)$ were used for the dynamic $\mathrm{CO}_{2}$ measurement. Furthermore, 36 soil cores $(\mathrm{h}=3 \mathrm{~cm}, \mathrm{r}=5 \mathrm{~cm}, \mathrm{n}=6)$ were used for the static chamber method.

At the beginning of the experiments both sample sets were saturated form beneath with distilled water and afterwards drained to a matric potential $(\Psi \mathrm{m})$ of $-6 \mathrm{kPa}$. Thus coarse pores (pore diameter $>50 \mu \mathrm{m}$ ) were air filled.

The GaFloCoD consists of a totally elastic metal bellow containing the soil core, an inlet and an outlet for percolated gas volumes as well as a ceramic suction plate at the bottom (Jasińska et al., 2006). A loading frame (Dual Column Tabletop Testing System 5569, Instron, USA) was used to compress the soil core that was enclosed by the bellows. The confined compression of the soil cores was carried out gradually with $1.5 \mathrm{~mm}$ increments at a compaction rate of $0.2 \mathrm{~mm} \mathrm{~min}^{-1}$. Four steps were applied; consequently, the soil cores were compacted up to $6 \mathrm{~mm}$ which equals a deformation of $10 \%$. Each step was maintained for $60 \mathrm{~min}$. During the compression experiment the bellow was percolated by $\mathrm{CO}_{2}$-free air with a constant flow rate of $220 \mathrm{ml} \mathrm{min}^{1}$. The absence of $\mathrm{CO}_{2}$ in the percolated air was achieved via its adsorption by soda lime granules. $\mathrm{CO}_{2}$ concentrations were measured by an NDIR gas analyzer (ADC 2250, BioScientific Ltd., UK) with a temporal resolution of $2 \mathrm{sec}$ before and after the air volume had passed through the soil sample in the bellow. Due to soil core storage the samples gaseous and liquid phases were enriched with $\mathrm{CO}_{2}$. Aiming to achieve a steady state where all detected $\mathrm{CO}_{2}$ is produced by the actual respiration of soil organisms, a pretreatment of the cores was necessary. This pre-treatment consisted of two phases percolation of:

- ambient air for at least $16 \mathrm{~h}$,

- $\mathrm{CO}_{2}$-free air for $3 \mathrm{~h}$.

These two phases were separated by an interruption of the percolation for $30 \mathrm{~min}$ while the gas analyzer was recalibrated. Since the steady state was not achieved, power functions (Eq. 2) were applied to the last hour of the second pre-treatment to take into account that a further dilution of $\mathrm{CO}_{2}$ occurred, which has been accumulated in the gaseous and liquid phases of the sample. The general form of this power function with $\mathrm{a}$ and $\mathrm{b}$ as fitting parameters and the time $t$ is:

$$
\mathrm{CO}_{2}(t)=a t \exp (-b) .
$$

Additionally, this function was used as a reference for the $\mathrm{CO}_{2}$ emission of the sample without the occurrence of mechanical loading (' $\mathrm{CO}_{2}$ emission calculated'). Total $\mathrm{CO}_{2}$ emissions per gram dry weight were calculated by multiplying the flow rate, the mean $\mathrm{CO}_{2}$ concentration and the experimental time divided by the mass of the dry soil.

Each predried (-6 kPa) soil core was placed in an air tight respiration chamber of approximately $800 \mathrm{~cm}^{3}$ and was incubated for 14 days at $24^{\circ} \mathrm{C}$. Greenhouse gas emissions were determined on three defined days (3rd, 7th and 14th). In order to avoid anaerobic conditions each chamber 
was opened daily for $15 \mathrm{~min}$. The loss of water caused by evaporation was compensated by adding a gravimetrically determined water volume to the filter paper at the bottom of the soil core. After this first incubation period the soil cores were compacted by a vertical stress-strain application of $400 \mathrm{kPa}$ to achieve plastic soil deformation. This stress was applied stepwise using a pneumatic multi-step oedometer device under drained conditions (Peth et al., 2010). The precompression stress $\left(\mathrm{P}_{\mathrm{c}}\right)$ was determined graphically according to Casagrande (1936, in Hartge and Horn 2014). Afterwards, soil cores were resaturated and drained to the originally preset matric potential of $\Psi_{\mathrm{m}}=-6 \mathrm{kPa}$ followed by a second incubation period of 14 days. In order to derive the soil-borne emissions, three replicates of blank values were gathered from chambers containing no soil cores but filter paper and $\mathrm{CO}_{2}$ traps. Of every result shown in the following sections the median of these three blank values was subtracted. Two methods were applied to this sample set for determining greenhouse gas emissions.

The volume of $\mathrm{CO}_{2}$ emitted from each soil core was determined by using an alkali trap inside the respiration chamber (for more detailed information see Pell et al. (2006). Therefore, $20 \mathrm{ml}$ of $0.1 \mathrm{M} \mathrm{NaOH}$ were filled into a polystyrol jar in an almost $\mathrm{CO}_{2}$-free atmosphere. Again, $\mathrm{CO}_{2}$-free atmosphere was achieved by streaming ambient air through soda lime granules. Respiration chambers were closed and incubated in darkness for $6 \mathrm{~h}$ at $24^{\circ} \mathrm{C}$. Afterwards the remaining $\mathrm{NaOH}$ was titrated with $0.2 \mathrm{M} \mathrm{HCl}$ to $\mathrm{pH} 8.2$ after the addition of $\mathrm{BaCl}_{2}(5 \mathrm{ml}, 0.5 \mathrm{M})$.

Gas aliquots $(20 \mathrm{ml})$ from the respiration chambers were sampled immediately before the titration. The samples were gathered using a syringe which was connected to the closed chamber by a Tconnector. The syringe was filled and emptied three times with chamber air in order to receive a homogeneous gas sample. The fourth filling of the syringe was analyzed by gas chromatography. Its measurement system consists of the chromatograph (Agilent 7890A, Agilent Technologies Inc., USA/China), an auto-sampler (CTC Analytics, Switzerland), and a personal computer for data processing using the software chem-station and chronos.

Each gas concentration was determined by an individual sensor: $\mathrm{CO}_{2}$ concentrations were measured using a thermal conductivity detector (TCD). $\mathrm{CH}_{4}$ concentrations were determined by oxidation in a flame ionization detector (FID). $\mathrm{N}_{2} \mathrm{O}$ concentrations were measured by an electron capture detector (ECD). Due to the sensors lower detection limit of $<1 \mathrm{ppb}, \mathrm{N}_{2} \mathrm{O}$ concentrations $<1 \mathrm{ppb}$ were set to $0 \mathrm{ppb}$.

Air conductivity $\left(\mathrm{k}_{\mathrm{a}}\right)$ was measured for both sample sets before and after compaction. The measurements were conducted by an air permeameter consisting of a set of float-block flowmeters under steady-state flow conditions (Peth, 2004). Air capacity was derived gravimetrically by subtracting the weight of the water-saturated sample and the weight of the sample after draining to $\Psi_{\mathrm{m}}=-6 \mathrm{kPa}$. Bulk density and total porosity were determined accord- ing to Hartge and Horn (2009). We assumed a density of $2.65 \mathrm{Mg} \mathrm{m}^{-3}$ for inorganic soil compartments and $1.3 \mathrm{Mg} \mathrm{m}^{-3}$ for soil organic carbon.

Disturbed, air-dried, and sieved soil $(<2 \mathrm{~mm})$ was used for standard soil parameters. $\mathrm{pH}$ values were determined in $0.2 \mathrm{M} \mathrm{CaCl}_{2}$. Total nitrogen was assayed photometrically using a flow injection analysis after Kjeldahl (Blume et al., 2010). Inorganic carbon was determined by Scheibler analysis. Soil organic carbon (SOC) concentration was calculated by subtracting the inorganic carbon concentration from total carbon concentration determined via dry combustion at $1200^{\circ} \mathrm{C}$ (Coulomat 702, Ströhlein instruments). Soil texture was determined complementary according to Schlichting et al. (1995) by combined sieving and sedimentation processes (pipette method) after removal of cementing substances.

The statistical software R (R Development Core Team, 2014) was used for plotting the results. Notched box and whisker plots are chosen for the graphical presentation indicating median (mid-line), 25th/75th percentile (lower/ upper border of the box), 95th and 5th percentile (whiskers), 1st and 99th percentile (x). The notches surrounding the medians provide a measure of the rough significance of differences between the values (McGill et al., 1978). If the notches about two medians do not overlap in this display, the medians are, roughly, significantly different at about a $95 \%$ confidence level. The data evaluation with the software $\mathrm{R}$ was based on an appropriate statistical mixed model (Verbeke and Molenberghs, 2000). The data were assumed to be normally distributed and to be heteroscedastic due to the different settlement steps (GaFloCoD experiments) and loading levels (static chambers). These assumptions based on a graphical residual analysis. The statistical model included the tillage intensities (NT, RT, CT), the depths (topsoil, subsoil) the loading levels (static chamber experiment; initial, immediately after compaction and final), and for the GaFloCoD experiments the settlement steps (1, 2, 3, and 4) and the loading status (further compaction being applied, compaction is maintained) as well as all their interaction terms (two-fold, three-fold and four-fold) as fixed factors. The cylinder (static chamber) and the interaction of cylinder and settlement steps (GaFloCoD experiments) were regarded as random factors. Based on this model, an analysis of variances (ANOVA) was conducted, followed by multiple contrast tests (Bretz et al., 2011; Schaarschmidt and Vaas, 2009) in order to compare the several levels of the influence factors, respectively. If a factor of interest had no significant interactions with the remaining factors, then the levels of these remaining factors were pooled. Mechanical stability data were evaluated on the factor levels treatment and depth by comparing their means using an ANOVA and Tukey test. Air conductivity data were evaluated on the factor levels compaction and depth by comparing their means using an ANOVA and Tukey test. 


\section{RESULTS AND DISCUSSION}

The subsoil of each treatment contained less soil organic carbon (SOC) compared with the topsoil (Table 1). While the RT treatment showed the highest SOC content for topsoil $\left(16.4 \mathrm{~g} \mathrm{~kg}^{-1}\right)$, the lowest SOC content was found in the CT subsoil $\left(9.9 \mathrm{~g} \mathrm{~kg}^{-1}\right)$. The inorganic carbon content (as $\mathrm{CaCO}_{3}$ ) ranged between $6.3 \mathrm{~g} \mathrm{~kg}^{-1}$ and $11.6 \mathrm{~g} \mathrm{~kg}^{-1}$, as was expected based on the neutral $\mathrm{pH}$ value. The total nitrogen contents showed a normal depth dependency. Again, the highest contents were found in the topsoil, while the subsoil contained less $\mathrm{N}_{\text {total }}$ which was especially distinct in the treatment with reduced tillage regime. Contradictory, this treatment showed the highest $\mathrm{pH}$ value and additionally, the $\mathrm{C}: \mathrm{N}$ ratio was the highest in this treatment and depth, while all other ratios vary between 11.2 and 13.8. conventionally tilled treatment (Fig. 2). These altered pore functions indicate plastic deformation, which is caused by exceeding the precompression stress $\left(\mathrm{P}_{\mathrm{c}}\right)$, mainly at the settlement steps three and four (Fig. 3). As shown in Fig. 1 these samples had the lowest soil strength in terms of precompression stress $\left(\mathrm{P}_{c}\right)$ for the corresponding depths.

Results of the dynamic compression experiment in terms of changing $\mathrm{CO}_{2}$ concentrations (measured and calculated), and void ratio by applied mechanical stresses (Fig. 3) show that $\mathrm{CO}_{2}$ evolved by soil samples and, therefore, biological activities of soil organisms vary to a large extent even when the same tillage regimes and depths are compared. The $\mathrm{CO}_{2}$ concentrations ranged between 44.9 and $74.3 \mathrm{ppm}$ for the NT topsoil at the beginning of the compression experiment (Fig. 3). In the further course of the compression experiment

T a b l e 1. Soil organic carbon (SOC), inorganic carbon concentration $\left(\mathrm{CaCO}_{3}\right)$, total nitrogen, as well as $\mathrm{C}: \mathrm{N}$ ratio and $\mathrm{pH}$ of soil treatments

\begin{tabular}{cccccc}
\hline \multirow{2}{*}{$\begin{array}{c}\text { Tillage system } \\
\text { Soil depth }(\mathrm{cm})\end{array}$} & $\mathrm{SOC}$ & $\mathrm{CaCO}_{3}$ & $\mathrm{~N}_{\text {total }}$ & & C:N \\
\cline { 2 - 3 } & & & & $\mathrm{pH}$ \\
\hline NT 10 & 14.5 & 9.3 & 1.3 & $11.2: 1$ & 7.05 \\
NT 40 & 11.1 & 9.3 & 0.9 & $12.8: 1$ & 7.34 \\
RT 10 & 16.4 & 6.3 & 1.2 & $13.4: 1$ & 7.01 \\
RT 40 & 12.5 & 7.5 & 0.6 & $21.8: 1$ & 7.44 \\
CT 10 & 15.1 & 11.6 & 1.3 & $12.0: 1$ & 7.10 \\
CT 40 & 9.9 & 10.8 & 0.8 & $12.8: 1$ & 7.19 \\
\hline
\end{tabular}

$\mathrm{NT}$ - no tillage, RT - reduced tillage, CT - conventional tillage.

The precompression stress $\left(\mathrm{P}_{\mathrm{c}}\right)$ significantly $(\mathrm{p}=0.05)$ increased with depth (Fig. 1). Furthermore, the soil strength of the reduced tillage subsoil significantly decreased in comparison with the other subsoils. Tillage reduced topsoil stability due to soil loosening (Hartge and Horn, 2014). Furthermore, it is known that platy structures in the plowed soils were strongest as could be proofed by the high $\mathrm{P}_{\mathrm{c}}$ as a consequence of soil compaction (Ehlers et al., 2000; Horn et al., 1995). Additionally, well-developed aggregates have a high internal strength eg caused by biological engineering (Nichols and Halvorson, 2013) and physical aggregate development (due to repeated shrinkage and swelling, Horn, 2004) explaining the high $\mathrm{P}_{\mathrm{c}}$ for the no tillage treatment (NT).

Both, the pore functions in terms of air conductivity (Fig. 2), and the pore capacities in terms of pore volumes (Table 2) showed no intense dependency on mechanical stress applied in the course of the GaFloCoD experiment. The influence of tillage treatment becomes obvious with respect to the total porosity and the air capacity. A significant reduction of the air conductivity caused by mechanical loading was detected in samples from the subsoil of the reduced tillage treatment as well as in the topsoil of the

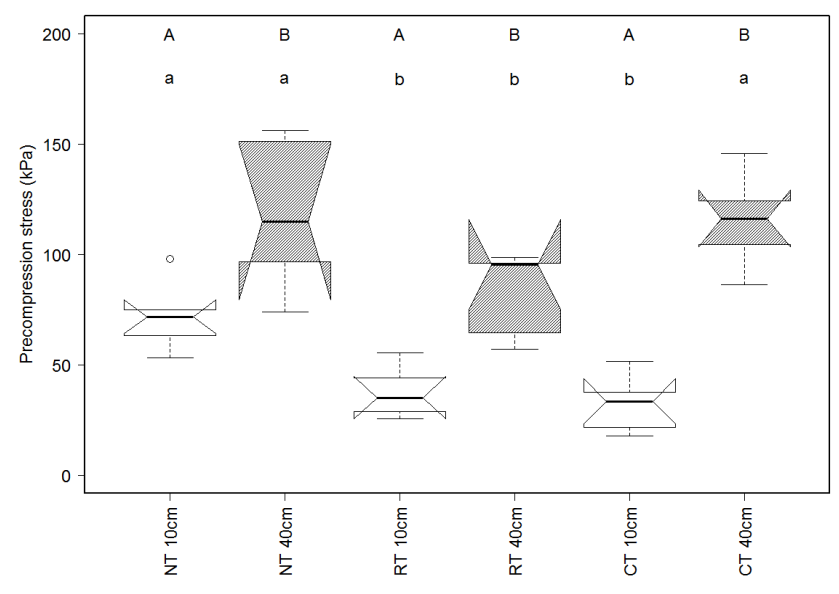

Fig. 1. Boxplots show management-specific internal soil strength as indicated by the precompression value $\left(\mathrm{P}_{\mathrm{c}}\right)$. White boxes represent the topsoil while gray boxes represent the subsoil $(n=6)$. Different uppercase letters indicate significant differences between depths in the same treatment, different lowercase letters indicate significant differences between treatments for corresponding depths according to Tukey test $(\mathrm{p} \leq 0.05)$. Explanations as in Table 1. 


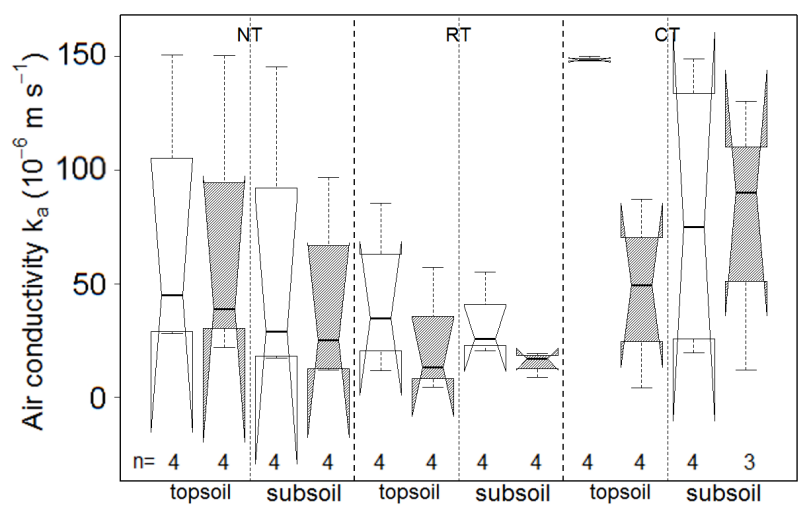

Fig. 2. Illustration of changes in air conductivity $\left(\mathrm{k}_{\mathrm{a}}\right)$ through mechanical stress for investigated management treatments. White boxes represent air conductivity prior to mechanical loading, gray boxes after the compression experiment in the GaFloCoD. Different letters indicate significant differences $(p \leq 0.05)$ for each treatment in topsoil and subsoil according to Tukey test. Explanations as in Table 1.
T a b l e 2. Mechanical stress induced changes of the pore size properties of samples used for dynamic experiments in the GaFloCoD. Initial total porosities $\left(\theta_{\text {total }}\right)$ and air capacities $\left(\theta_{\text {air }}\right)$ as well as the loss of pore volume caused by mechanical loading $(\triangle \mathrm{PV})$

\begin{tabular}{cccc}
\hline & \multicolumn{2}{c}{ Before loading } & $\begin{array}{c}\text { During } \\
\text { maximum } \\
\text { Tillage system } \\
\begin{array}{c}\text { Soil depth } \\
(\mathrm{cm})\end{array}\end{array}$ \\
\cline { 2 - 4 } & $\theta_{\text {total }}$ & $\theta_{\text {air }}$ & $\Delta$ PV \\
\cline { 2 - 4 } compression
\end{tabular}

Explanations as in Table 1.

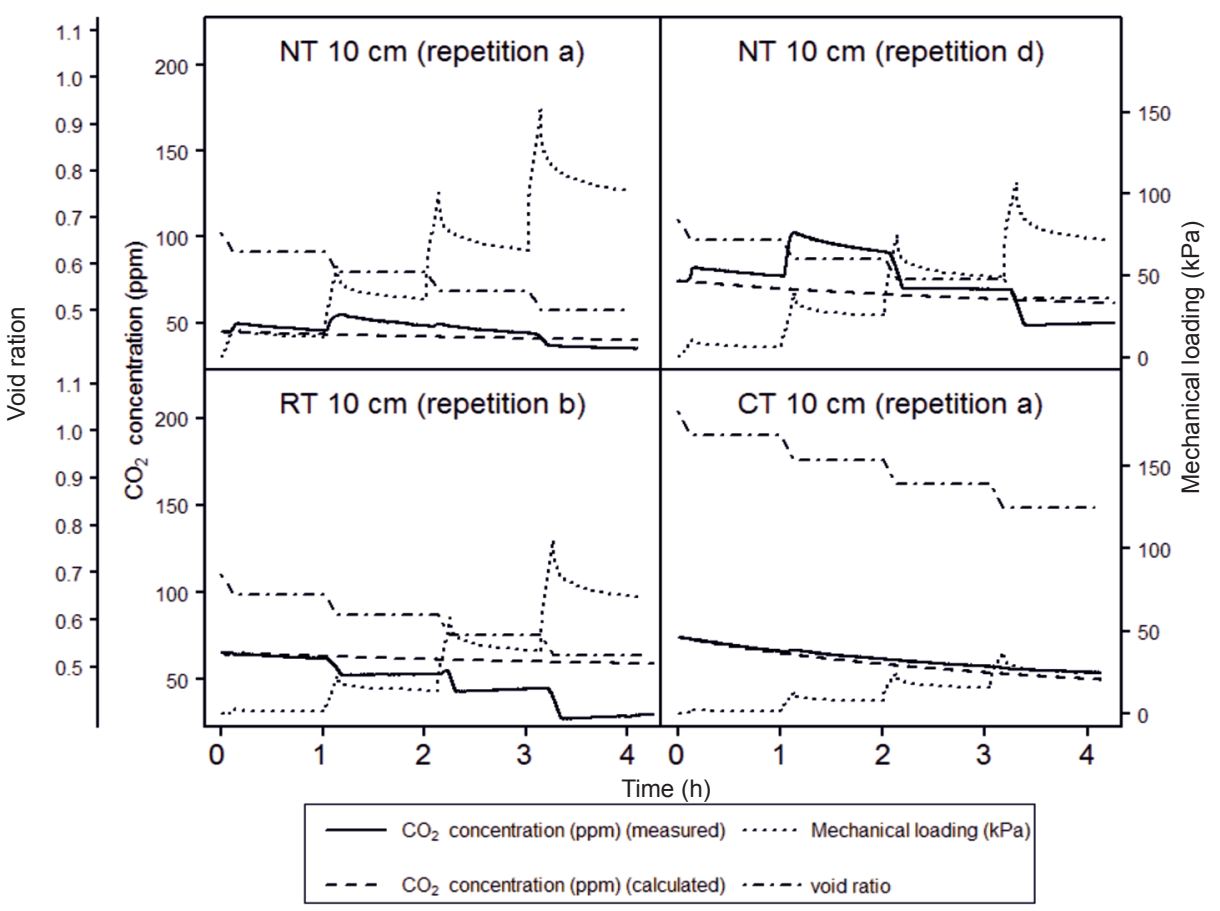

Fig. 3. Exemplary representation of results of the dynamic measurements in the GaFloCoD. Measured and calculated (according to Eq. (2)) $\mathrm{CO}_{2}$ concentrations in ppm as well as mechanical loading in $\mathrm{kPa}$ and void ratios are shown. Explanations as in Table 1 .

in the GaFloCoD for some samples we found an increase of the biological activity for the first settlement steps followed by a decrease (Fig. 3). Furthermore, some samples showed a reduction of biological activity with every settlement step (NT topsoil repetition c; NT subsoil repetition c; RT topsoil repetition b; RT subsoil repetition $b$ and $c$ ), while some samples showed nearly no reaction (NT subsoil repetition $\mathrm{b}, \mathrm{CT}$ topsoil repetition a). These various patterns can not only be explained by soil heterogeneity in terms of distribution of pore sizes and SOC. Therefore, to determine the influence of compactible forces on biological activity we need to consider the relative changes of $\mathrm{CO}_{2}$ emissions (ie $\mathrm{CO}_{2}$ emission measured divided by $\mathrm{CO}_{2}$ emission as calculated from the power functions) depending on the tillage regime and investigated depths.

Figure 4a shows the relative mean changes of $\mathrm{CO}_{2}$ emissions for every settlement step at that point of time when the highest mechanical stresses were measured. That is when the final settlement of every step is reached. Figure $4 b$ shows the relative mean changes of $\mathrm{CO}_{2}$ emission for 


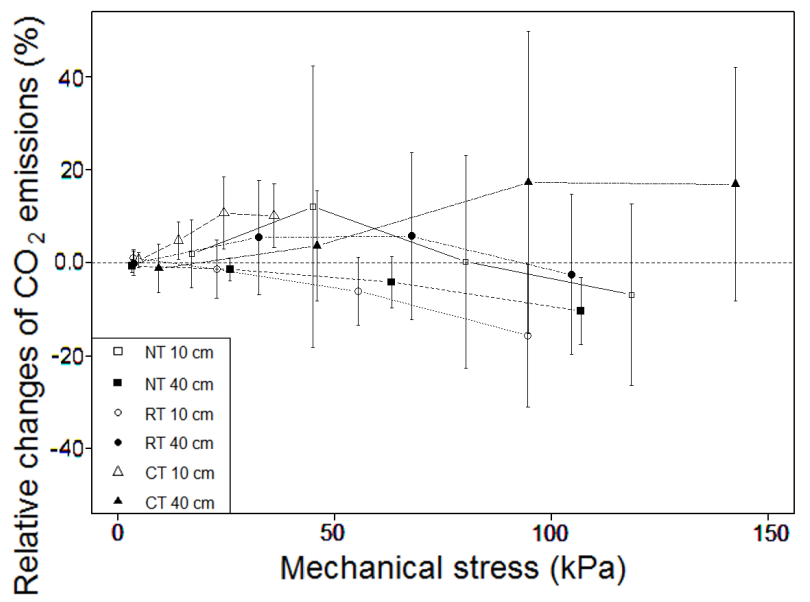

b

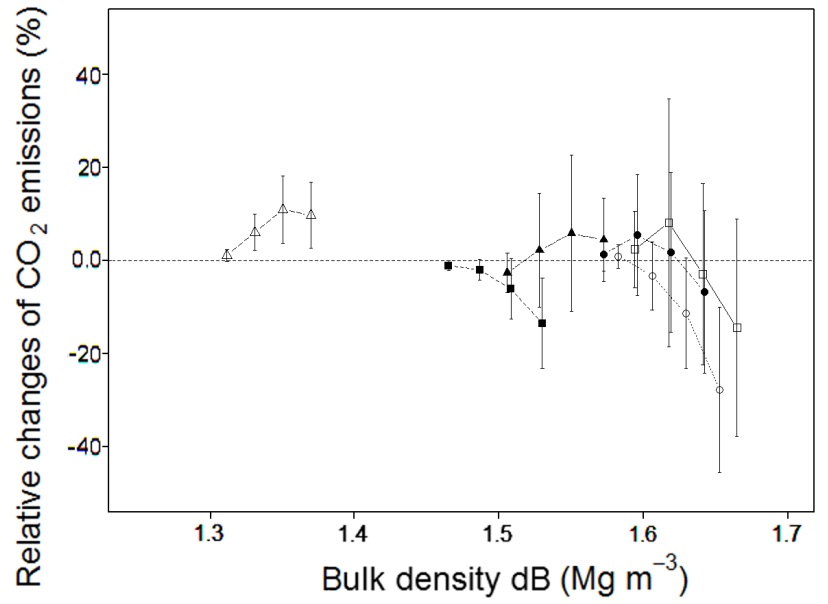

Fig. 4. Arithmetic mean changes (\%) of measured $\mathrm{CO}_{2}$ emissions with standard deviations (error bars) in dependency of the: a - mean applied maximal mechanical stress $(\mathrm{kPa})$ and $\mathrm{b}$ - mean bulk density $\left(\mathrm{Mg} \mathrm{m}^{-3}\right)$ for every settlement step $(1.5,3.0,4.5$ and $6.0 \mathrm{~mm})$. Explanations as in Table 1.

a complete settlement step as a function of bulk density. Within the same depth of each treatment the pattern of these curves is roughly similar but the relative changes of $\mathrm{CO}_{2}$ emissions shown in Fig. 4a indicate a more intensive $\mathrm{CO}_{2}$ emission during soil compression. This is caused by a local maximum in $\mathrm{CO}_{2}$ emission at that point of time when the additional stress is applied. For both depths of the CT treatment $\mathrm{CO}_{2}$ emissions increased, the more the soil was compressed. The opposite was found in the topsoil of the RT treatment and the subsoil of the NT treatment where the $\mathrm{CO}_{2}$ emission decreased the more the soil was compressed. For the topsoil of the NT and the subsoil of the RT treatment an increased $\mathrm{CO}_{2}$ emission at the first step followed by a decrease even below the reference value $\left(\mathrm{CO}_{2}\right.$ calculated) was observed with further stress application (Fig. 4).

The application of mechanical stress led generally to a reduction in the geometric mean of the $\mathrm{CO}_{2}$ emissions over the entire experimental time in both depths of the NT and RT treatment (Table 3). The opposite occurred in the CT treatment. Additionally, the mechanical stress applied to achieve the deformation of $10 \%$ is lowest in the topsoil and highest in the subsoil of this treatment. Therefore, the influence of tillage becomes obvious. The higher the energy input due to tillage, the more aggregates are disrupted leading to a weakening of the soil strengths in the topsoil (Watts et al., 1999). With decreasing soil strength, less mechanical stress is needed for soil compression. According to this, the lowest stress for compaction was found in the topsoil of the RT and the CT treatment. Additionally, the formation of a platy structure below the tilled layer is well documented (Horn et al., 2000) and characterized by high soil strength due to soil compression, and more horizontally orientated
T a b l e 3. Management-specific geometrical mean of $\mathrm{CO}_{2}$ release during the GaFloCoD experiment and the arithmetical mean with standard deviations of the maximal applied mechanical stress resulting in a soil volume deformation of $10 \%$.

\begin{tabular}{cccc}
\hline \multirow{2}{*}{$\begin{array}{c}\text { Tillage system } \\
\text { Soil depth } \\
(\mathrm{cm})\end{array}$} & $\begin{array}{c}\mathrm{CO}_{2} \text { emission } \\
\text { (measured) }\end{array}$ & $\begin{array}{c}\mathrm{CO}_{2} \text { emission } \\
\text { (calculated) }\end{array}$ & $\begin{array}{c}\text { Mechanical } \\
\text { stress required }\end{array}$ \\
\cline { 2 - 4 }$\left(\mu \mathrm{g} \mathrm{CO}_{2} \mathrm{~g}^{-1} \mathrm{DM} \mathrm{h}^{-1}\right)$ \\
\hline NT 10 & $2.33 \pm 1.08$ & $2.49 \pm 1.12$ & $120.3 \pm 24.8$ \\
NT 40 & $2.88 \pm 1.05$ & $3.03 \pm 1.04$ & $109.0 \pm 28.3$ \\
RT 10 & $1.85 \pm 1.28$ & $2.07 \pm 1.29$ & $94.8 \pm 8.3$ \\
RT 40 & $2.43 \pm 1.36$ & $2.46 \pm 1.41$ & $105.6 \pm 17.3$ \\
CT 10 & $2.87 \pm 1.16$ & $2.70 \pm 1.19$ & $37.2 \pm 10.4$ \\
CT 40 & $2.37 \pm 1.20$ & $2.26 \pm 1.07$ & $147.7 \pm 47.6$ \\
\hline
\end{tabular}

DM - dry mass. Other explanations as in Table 1.

coarse pores. This contrasts with the high soi 1 stability due to aggregate formation and biological engineering which are characteristic of well-developed soils (Six et al., 2004). In this regard, samples of variants that were not (NT), or were less (RT) influenced by soil tillage practices showed several vertically orientated biopores and a higher soil strength. Generally high soil stability requires higher mechanical stress in order to achieve the deformation of $10 \%$ (Table 3, last column).

Soil deformation coincides with a shift in the pore size distribution, and may result in a redistribution of the liquid and gaseous phases in soils. If coarse air-filled pores are compressed until their size becomes smaller than the largest water-filled pore, a more negative matric potential 
T a b l e 4. Arithmetic means with standard deviations of the maximum reduction of the matric potential $\Delta \Psi_{\mathrm{m}}=\Psi_{\mathrm{m}(\text { minimum })}$ $\Psi_{\mathrm{m}(\text { start })}$ as observed during the mechanical loading (400 kPa)

\begin{tabular}{cc}
\hline $\begin{array}{c}\text { Tillage system } \\
\text { Soil depth }(\mathrm{cm})\end{array}$ & $\Delta \Psi_{\mathrm{m}}(\mathrm{kPa})$ \\
\hline NT 10 & $-0.23 \pm 0.57$ \\
NT 40 & $-1.05 \pm 1.03$ \\
RT 10 & $-0.01 \pm 0.03$ \\
RT 40 & $-1.66 \pm 1.84$ \\
CT 10 & $-1.01 \pm 1.39$ \\
CT 40 & $-1.03 \pm 0.80$ \\
\hline
\end{tabular}

Explanations as in Table 1.

is observed (Fazekas and Horn, 2005). By applying further soil stress the matric potential increases despite constant gravimetric water content (Fazekas and Horn, 2005). However, changes in matric potential were not determined during the GaFloCoD experiment but can be derived approximately from measurements conducted in the course of the static chamber experiments. Focusing on the applied soil stresses in the GaFloCoD experiment, a constant or slightly increased negative matric potential for samples of both depths for the NT as well as for the RT treatment was observed using the static chamber method, while samples of both depths of the conventionally tilled treatment showed a decreased negative matric potential (Table 4). As a consequence of the altered water saturation and pore size distribution including pore connectivity we can also find altered $\mathrm{CO}_{2}$ emissions which can be explained in combination with the biological activity. Two counteracting factors need to be considered (for a schematic overview see Mordhorst et al., 2014):

- a reduction of air-filled pores causes a reduction of air conductivity and therefore oxygen supply might be restricted. This results in a reduced biological activity, since oxygen supply is a limiting factor for biological activity. As a consequence lower $\mathrm{CO}_{2}$ emissions can be detected;

- a reduction of coarse air-filled pores results in an increase of finer pore sizes which may have a microhabitat function because the size of bacteria and fungi is equivalent to medium-sized pores $(0.2-10 \mu \mathrm{m})$. As observed by Pengthamkeerati et al. (2011) the biological activity in terms of $\beta$-Glucosidase activity and soil microbial biomass can increase as a consequence of such shifting to more medium-sized pores. As a consequence higher $\mathrm{CO}_{2}$ emissions can be detected.

It is well known that, due to increased soil stress, the reduction of oxygen supply becomes predominant. However, the origins of these pores differ and also their internal soil strength and functions. Also the fluxes and gas composition may differ (Stępniewski, 2002, Stępniewski and Stępniewska, 2009). The more intensely these coarse pores become compressed and more medium pores are formed, the more the water binding forces as well as the flux intensity and composition are also altered. Coarse pores can be created by ploughing as well as by biological engineering eg by drilling activities of earthworms or growing plant roots. It was not determined, whether existing pores had been formed by plants or drilling activities of earthworms. According to Bischoff and Wulffen (unpublished) who found 116 lumbricid burrows on each square meter of the NT treatment while the same area of the CT treatment showed 32 lumbricid burrows it is expected that coarse pores were mainly formed by earthworms. Ehlers et al. (1983) found that biological coarse pores are known to have inherent high strength. These pores act as microbiological hotspots (Kuzyakov and Blagodatskaya, 2015) even if distinct differences between the spatial orientations of earthworm burrows depending on the applied tillage regime exist. Ehlers et al. (2000) found that burrow orientation tends to become closer to the horizontal direction, if there are penetration barriers like platy structures. According to Hartge and Bohne (1983), only vertical burrows are characterized by high stability while horizontal ones show lower stability. Therefore, under elastic strain the compression of samples of the NT and RT treatment resulted in an increasing (less negative) matric potential but in a decreased biological activity as measured by $\mathrm{CO}_{2}$ concentrations. The opposite is true for samples of the conventionally tilled treatment. Here, a decreased (more negative) matric potential and increased biological activity as measured by $\mathrm{CO}_{2}$ concentrations were found which may be explained by the fact that for this treatment coarse pores were predominantly reduced in size and became water-filled which may result in altered microhabitat activities and resulting higher $\mathrm{CO}_{2}$ emissions. However, such formation of continuous pores due to plowing is not rigid and may be changed after relatively short time again. Thus it can be assumed generally that these anthropogenically formed coarse pores with their lower internal strength in comparison with naturally developed pores will be shifted predominantly to finer pores that act as new microhabitats. Oxygen supply was maintained by remaining coarse pores as can be seen in Table 2. The maximum loss of pore volume $(\Delta \mathrm{PV})$ did not exceed the fraction of coarse pores. But still there was a loss of soil function in terms of air conductivity (Fig. 2) which is significant at the topsoil of the conventionally tilled treatment. Contrary to this the loss of microhabitable pores showed obviously decreased $\mathrm{CO}_{2}$ emissions as found for both depths of the NT and the RT treatment. However, the statistical analyses showed no significant difference for both, tillage intensities and depths.

The following section refers to results concerning the second experimental setup (static chambers). In Table 5 the mean changes and standard deviations of total porosity $\left(\theta_{\text {total }}\right)$, air capacity $\left(\theta_{\text {air }}\right)$ and air conductivity $\left(\mathrm{k}_{\mathrm{a}}\right)$ during the 
T a b l e 5. Mechanical loading $(400 \mathrm{kPa})$ induced mean changes in total porosity $\left(\theta_{\text {total }}\right)$, air capacity $\left(\theta_{\text {air }}\right)$, water filled pore space (WFPS), and air conductivity $\left(\mathrm{k}_{\mathrm{a}}\right)$ as determined in the course of the static chamber experiment. Values are presented as arithmetic mean and standard deviation, with exception of air conductivity presented as geometric mean with standard deviation based on their logarithmic terms. IMT means immediately after soil compaction

\begin{tabular}{|c|c|c|c|c|c|c|c|c|c|}
\hline \multirow{3}{*}{$\begin{array}{c}\text { Tillage } \\
\text { system } \\
\text { Soil depth } \\
\quad(\mathrm{cm})\end{array}$} & \multicolumn{4}{|c|}{ Before loading (initial) } & \multicolumn{2}{|c|}{ After compaction (IMT) } & \multicolumn{3}{|c|}{ After reequilibrating (final) } \\
\hline & $\theta_{\text {total }}$ & $\theta_{\text {air }}$ & $\mathrm{k}_{\mathrm{a}}\left(10^{-6}\right)$ & WFPS & $\theta_{\text {total }}$ & $\mathrm{k}_{\mathrm{a}}\left(10^{-6}\right)$ & WFPS & $\theta_{\text {total }}$ & $\theta_{a i r}$ \\
\hline & \multicolumn{2}{|c|}{ (vol.-\%) } & $\left(\mathrm{m} \mathrm{s}^{-1}\right)$ & \multicolumn{2}{|c|}{ (vol.-\%) } & $\left(\mathrm{m} \mathrm{s}^{-1}\right)$ & \multicolumn{3}{|c|}{ (vol.-\%) } \\
\hline \multicolumn{10}{|c|}{ Arithmetic mean } \\
\hline NT 10 & 43.8 & 5.9 & 26.3 & 86.5 & 35.2 & 1.2 & 84.3 & 36.7 & 5.8 \\
\hline NT 40 & 46.8 & 8.3 & 37.5 & 82.9 & 37.2 & 2.7 & 86.7 & 40.4 & 5.4 \\
\hline RT 10 & 48.6 & 11.3 & 20.1 & 77.3 & 35.9 & 0.2 & 84.3 & 39.0 & 6.1 \\
\hline RT 40 & 43.8 & 6.7 & 25.9 & 84.7 & 33.9 & 2.0 & 86.4 & 35.5 & 4.8 \\
\hline CT 10 & 49.6 & 12.4 & 35.9 & 75.2 & 35.7 & 0.9 & 77.4 & 39.2 & 8.9 \\
\hline CT 40 & 45.3 & 7.0 & 18.4 & 84.7 & 35.3 & 1.1 & 86.4 & 38.9 & 5.3 \\
\hline \multicolumn{10}{|c|}{ Standard deviation } \\
\hline NT 10 & 1.9 & 2.0 & 3.0 & 5.0 & 2.5 & 4.6 & 4.0 & 1.2 & 1.5 \\
\hline NT 40 & 2.5 & 8.3 & 2.5 & 16.1 & 1.4 & 4.3 & 2.0 & 3.4 & 1.0 \\
\hline RT 10 & 4.0 & 5.6 & 3.6 & 9.9 & 4.2 & 3.1 & 4.8 & 0.9 & 1.9 \\
\hline RT 40 & 1.5 & 2.1 & 2.4 & 4.7 & 0.7 & 6.9 & 1.0 & 1.1 & 0.4 \\
\hline CT 10 & 4.4 & 3.8 & 2.6 & 6.4 & 2.2 & 11.1 & 7.9 & 2.8 & 3.2 \\
\hline CT 40 & 1.3 & 4.8 & 2.1 & 10.2 & 1.2 & 1.8 & 2.2 & 1.3 & 0.9 \\
\hline
\end{tabular}

Explanations as in Table 1.

experimental procedure revealed an increase of the waterfilled pore space $\left(\right.$ WFPS $\left.=\left(\theta_{\text {total }}-\theta_{\text {air }}\right) \theta_{\text {total }}^{-1}\right)$ with repeated stress application. One exception was found for the samples of the NT topsoil. In this case a lowered WFPS means that mainly finer pores $(<50 \mu \mathrm{m})$ were reduced in size which may be explained by the high rigidity of naturally developed coarse pores.

Based on dry mass of each sample the $\mathrm{CO}_{2}$ emissions of the static chamber method were at least twice as high as the $\mathrm{CO}_{2}$ emissions derived from the dynamic method (Table 3 and Fig. 5) because: there is

- a hatch of earthworms which was observed during the incubation of soil cores especially in topsoil samples at the initial state (Fig. 6), and

- a smaller dilution of $\mathrm{CO}_{2}$ which was enriched in the liquid and gaseous phases in comparison with the dilution due to the pre-treatment of soil cores used for dynamic measurement;

- soil samples used in the static chamber method have a larger surface/volume ratio caused by a lower sample height, therefore, pathways for diffusion were shorter.

As a consequence of mechanical loading with up to $400 \mathrm{kPa}$ (Fig. 5, initial versus immediately after stress application (IMT)) there is an obvious reduction in bio- logical activity as measured by emitted $\mathrm{CO}_{2}$ for all tillage treatments and both. Mordhorst et al. (2014) also described such effects using almost the same experimental setup. It was proven by the statistical model that this reduction is significant for the soil cores from each tillage intensity and sampling depth. The p-value for topsoils of all tillage intensities is $\leq 0.0001$. For subsoils we found $p=0.00631(\mathrm{NT})$, $\mathrm{p}=0.00499(\mathrm{RT})$ and $\mathrm{p}=0.00603(\mathrm{CT})$. Lower air conductivity as shown in Table 5 and, therefore, a less intensive aeration of the soil seems reasonable for lowered $\mathrm{CO}_{2}$ emissions since gas exchange is important to biological activity. After reequilibrating the matric potential to $-6 \mathrm{kPa}$ (Fig. 6, final) a depth-dependent soil reaction was found. While the emitted concentration of $\mathrm{CO}_{2}$ by soil cores was again lowered in the topsoil of every tillage treatment, the opposite occurred in the subsoil. This is only significant for RT $(\mathrm{p} \leq 0.0001)$. The emitted concentration of $\mathrm{CO}_{2}$ of all topsoil soil cores still remained significantly lower in comparison with the initial state $(p \leq 0.0001)$. This result is contradictory to the results of Mordhorst et al. (2014) who found an explicit increase after the reequilibration of samples of two depths (10-15 and 35-40 cm) of a Stagnic Luvisol with loamy sand, and for samples of a Haplic Luvisol with clayey silt $(10-15 \mathrm{~cm})$. On the other hand subsoils of the 


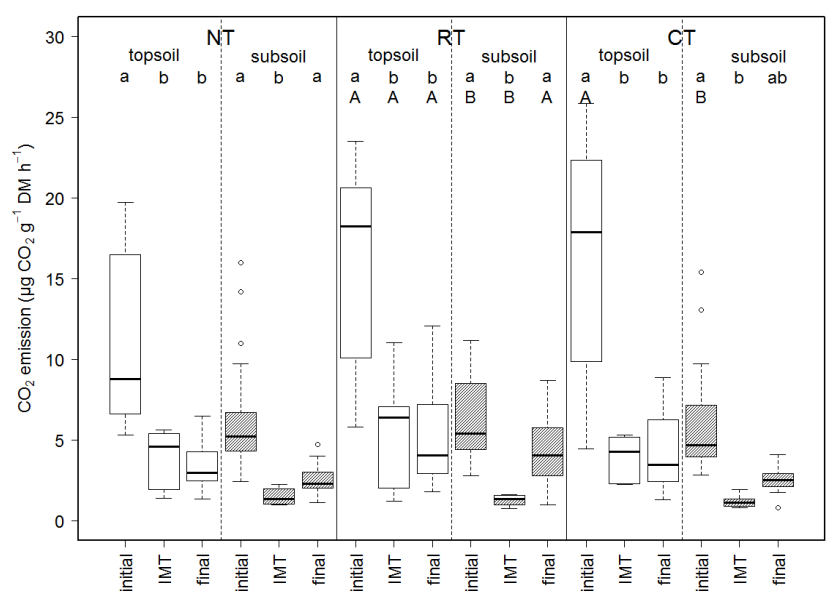

Fig. 5. Concentration of $\mathrm{CO}_{2}$ in $\mu \mathrm{g} \mathrm{CO}_{2} \mathrm{~g}^{-1} \mathrm{DM} \mathrm{h}^{-1}$, measured using an alkali trap in the inside of the respiration chamber. Results of single sampling days were merged together thus the situation before (initial) and after (final) the soil had been compacted are based on three repetitions for every one of the three tillage intensities (NT, RT, CT) and the two depths (topsoil, subsoil), while the results shown for the situation immediately after soil compaction (IMT) are based on one repetition. Different lower case letters indicate significant differences for the loading level (initial, IMT, final) of each depth and tillage intensity. Different upper case letters indicate significant differences for the depth of each tillage intensity and loading level.

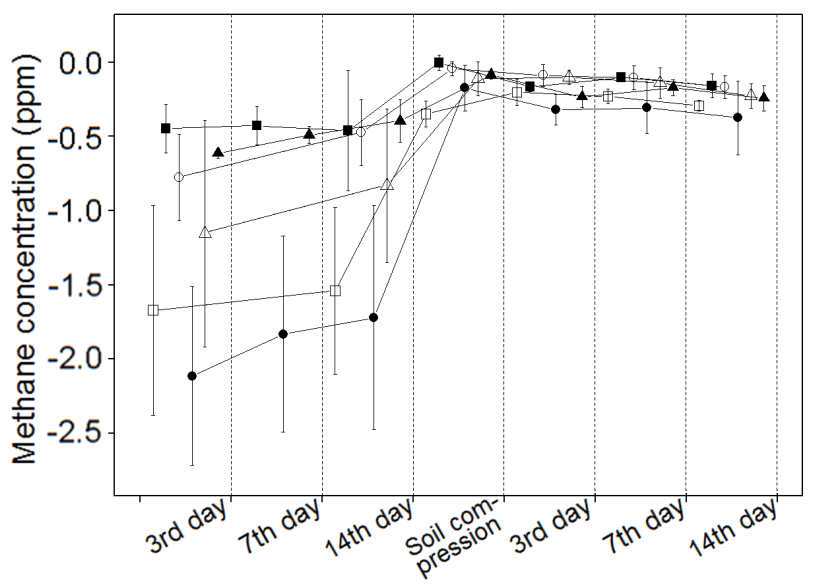

Fig. 6. Results of the gas chromatography measurements of $\mathrm{CH}_{4}$ concentrations depending on tillage treatment at different incubation time steps. Negative values indicate methane consumption. Explanations as in Table 1, legend as in Fig. 4.

NT and RT treatment showed an increase after reequilibration, resulting in higher $\mathrm{CO}_{2}$ emissions, significantly higher compared with IMT (NT: $p=0.0486$; RT $\leq 0.0001)$ but not significantly different to initial. Regarding Table 5 the compaction-induced decrease in total pore volume was accompanied by decreasing air conductivity (initial versus IMT). After the reequilibration an increase of total pore volume was evident compared with IMT but a decrease in comparison with the initial state was detected. A reduc- tion of air capacity (initial versus final) for all investigated treatments and depths was found, except for the NT topsoil. Consequently, the fraction of coarse pores $(>50 \mu \mathrm{m})$ in the topsoil of the NT treatment remained stable while finer pore size fractions $(0.2-50 \mu \mathrm{m})$ were predominately affected by loading (Peth et al., 2010). As a consequence the WFPS decreased for this treatment while the WFPS in all other treatments increased (Table 5).

The highest biological activity is usually located near the surface (Suarez and Simunek, 1993) as it was observed for all investigated tillage regimes at this experimental setup. Due to exceeding the precompression stress during compression with up to $400 \mathrm{kPa}$ an aggregate breakdown occurred (Hartge and Horn, 2014). Aggregates protect soil organic carbon (SOC) by encrusting at the inner aggregate layer (Six et al., 2004). Besides the mechanical aggregate breakdown, a biological disruption of aggregates is known. Higher biological activity led to an increased aggregate turn-over time. But due to a supply of plant exudates and crop residues, the carbon stock is continuously replenished. Therefore, a larger release of labile organic particles caused by aggregate breakdown is expected for the topsoil than for the subsoil. Higher $\mathrm{CO}_{2}$ emissions at the topsoil in comparison with the subsoil further prove this theory ( $p \leq 0.0001$ for RT and CT at initial stadium; $p=0.00105$ for RT immediately after compaction). It is well known that subsoils show a more intensive rebound after mechanical unloading and reequilibrating which is caused by a higher precompression stress. The sample's rebound leads to a reestablishment of the conducting pore volume, and therefore to a better gas exchange and partially compensates oxygen limitations. This results in an increase of the soil biological activity verified by an increase in $\mathrm{CO}_{2}$ emissions after reequilibrating (IMT versus final) the subsoil samples.

$\mathrm{CO}_{2}$ emissions determined by the alkali trap and gas chromatography (data not shown) were in good accordance, as long as less than $20 \%$ of the $\mathrm{NaOH}$ had been neutralized. Even if earthworms found on the soil samples' surface were removed, the former had influenced the gas composition of the soil pores before. These interactions can be derived from the exceeding threshold during incubating the soil cores and the resulting almost complete neutralization of the $\mathrm{NaOH}$.

Mechanical stress induced changes in pore continuity, water saturation, altered microbial activity and composition may under more anaerobic conditions also result in the formation of methane and nitrous oxide, although especially agricultural soils are usually $\mathrm{CH}_{4}$ sinks (Powlson et al., 1997). This can be confirmed by the results of this study. The $\mathrm{CH}_{4}$ concentration in all static chambers with soil was lower compared with chambers without soil, which means that $\mathrm{CH}_{4}$ consumption occurred (Fig. 6). The ability of soil microbes to consume $\mathrm{CH}_{4}$, however, is heavily reduced as a consequence of mechanical loading and remained reduced even after one cycle of swelling and shrinkage 


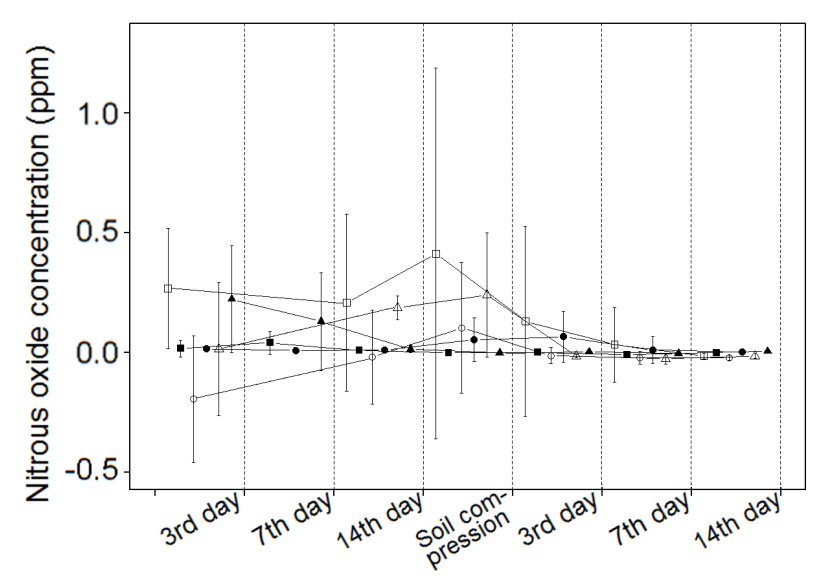

Fig. 7. Results of the gas chromatography of $\mathrm{N}_{2} \mathrm{O}$ concentrations depending on tillage treatment at different incubation time steps. Explanations as in Table 1, legend as in Fig. 4.

( $p \leq 0.0001$ for subsoil of RT and topsoil of NT; $p=0.0009$ for topsoil of CT if initial stadium is compared with IMT and $\mathrm{p}=0.0019$ if initial is compare with final stadium). How far a change in the reactions occurred with depth could not be finally determined as the highest $\mathrm{CH}_{4}$ consumption was found in the subsoil of the RT and the topsoil of the NT treatment. Contrary to the topsoil of the NT treatment its subsoil is consuming the least $\mathrm{CH}_{4}$. These differences can have multiple reasons that are discussed in the following. $\mathrm{CH}_{4}$ oxidization is positively correlated with the oxygen concentration of the environment (Mancinelli and McKay, 1985). In this study no obvious correlation could be ascertained between $\mathrm{CH}_{4}$ consumption and single soil functions influencing the oxygen supply namely air capacity, air conductivity, water saturation or bulk density. Therefore, rather variations in total $\mathrm{CH}_{4}$ production, interactions of substrates and products of metabolism, differences in pore functions (microhabitat and gas exchange) and necessarily of the abundance and activity of involved organisms seem responsible for the observed results. However, two reasons for changes in $\mathrm{CH}_{4}$ consumption can generally be assumed, either an increased $\mathrm{CH}_{4}$ production or a decreased $\mathrm{CH}_{4}$ oxidation, both due to lowered $\mathrm{O}_{2}$ supply caused by decreasing air conductivity, and a higher bulk density. As a consequence of enhanced anaerobic sites, a gained $\mathrm{N}_{2} \mathrm{O}$ production was expected but not found in general (Fig. 7). Therefore, further arguments are needed to explain the changes in $\mathrm{CH}_{4}$ emissions.

In aerobic soils, the highest degree of methanotrophy is usually observed in deeper soil layers (Bender and Conrad, 1994). Soil cores of the subsoil in the reduced tillage treatment showed the highest $\mathrm{CH}_{4}$ consumption and the least concentration of $\mathrm{N}_{\text {total }}$ (Table 1). Lacking specificity of the $\mathrm{CH}_{4}$ oxidizing enzyme, the $\mathrm{CH}_{4}$ monooxygenase (MMO), leads to the ability of methanotrophs to oxidize ammo- nium $\left(\mathrm{NH}_{4}^{+}\right)$to nitrite. As shown by King and Schnell (1994) $\mathrm{NH}_{4}^{+}$inhibits the $\mathrm{CH}_{4}$ oxidization in cell cultures of for example Methylobacter albus and Methylosinus trichosporium. Furthermore, compared with cell cultures the $\mathrm{CH}_{4}$ oxidation in soils appears to be more sensitive to $\mathrm{NH}_{4}^{+}$inhibition (King and Schnell, 1994). According to Nesbit and Breitenbeck (1992) the inhibitory effect of $\mathrm{NH}_{4}^{+}$persists for long periods, even after the available $\mathrm{NH}_{4}^{+}$dissipates. Therefore, there is a kind of competitive interaction between $\mathrm{CH}_{4}$ and $\mathrm{NH}_{4}^{+}$oxidization for the MMO (Dalton, 1977) if previously encrusted and thus protected organic carbon is mineralized and, therewith, $\mathrm{NH}_{4}^{+}$ is released. With a view to $\mathrm{N}_{2} \mathrm{O}$ the subsoil of the reduced tilled treatment showed no relevant emissions (Fig. 8) even after the soil was heavily compacted. This leads to the suggestion that there is no usable substrate for denitrificants and therefore, a less effective inhibition of $\mathrm{CH}_{4}$ oxidation through methanotrophs occurred. This might be one reason for increasing $\mathrm{CH}_{4}$ consumption after the samples were resaturated and drained to standard matric potential $(-6 \mathrm{kPa})$. Contrary to this, the topsoil of the no tilled treatment showed increased $\mathrm{N}_{2} \mathrm{O}$ emissions after compaction. By exceeding the precompression stress aggregates were destroyed. As a consequence SOC can be metabolized by soil microbes which led to a release of nutrients, eg $\mathrm{NH}_{4}^{+}$nitrogen. $\mathrm{CH}_{4}$ consumption had obviously been lowered again after resaturation and drainage. This could be caused by $\mathrm{NH}$ induced inhibition of MMO.

\section{CONCLUSIONS}

1. Soil compaction has various influences on microbial activity and, therefore, on soil processes like greenhouse gas emission or mineralization of soil organic carbon.

2. Mechanical stresses lead to an increase or to a decrease of biological activity depending on the stability of pore architecture and on the applied soil stress. If the precompression stress and thus the inherent soil strength are not exceeded, two opposite soil reactions can be observed. For the conventional tillage treatment, $\mathrm{CO}_{2}$ emissions increased. Soils with a stable macropore network showed a reduction of biological activity. We concluded that the soil reaction under elastic strain depends on the change in the fraction of medium-sized pores that act as microhabitats. The decrease of predominantly coarse pores leads to an increase in medium-sized pores and thus to an increase of the biological activity, and vice versa. Furthermore, if previously air-filled pores become water saturated the gas exchange is restricted resulting in a decrease of the soil diffusion coefficient which may explain the decrease of biological activity as measured by $\mathrm{CO}_{2}$ emissions.

3. If plastic deformation occurs, a loss of soil functions (total porosity, air capacity and air conductivity) can be observed. This is accompanied by a reduction of biological activity, which might be not only a consequence of 
lowered aeration but also a reduction of medium-sized pores. Furthermore, a depth dependency was found, probably caused by the release of previously encrusted and, thereby, protected organic carbon. In addition, a nearly complete loss of $\mathrm{CH}_{4}$ consumption was observed which might be caused by the loss of pore functions and an increase in nitrogen compounds. Furthermore, alterations in greenhouse gas emission due to different tillage practice disappeared.

4. The direct link between soil strength and microbial activity as well as its composition are a perfect marker for soil rigidity and the transition to the following irreversible soil degradation processes.

\section{REFERENCES}

Acha V., Alba J., and Thalasso F., 2002. The absolute requirement for carbon dioxide for aerobic methane oxidation by a methanotrophic-heterotrophic soil community of bacteria. Biotechnology Letters, 675, 675-679.

Bender M. and Conrad R., 1994. Methane oxidation activity in various soils and fresh-water sediments-occurrence, characteristics, vertical profiles, and distribution on grain-size fractions. J. Geophys. Res. Atmos., 99(1994) 16531-16540.

Blume H.-P., Stahr K., and Leinweber P., 2010. Bodenkundliches Praktikum. Spektrum, Heidelberg.

Bretz F., Hothorn T., and Westfall P., 2011. Multiple Comparisons Using R. Chapman and Hall Book, CRC Press, Boca Raton, London, New York.

Dalton H., 1977. Ammonia oxidation by the methane oxidizing bacterium Methylococcus capsulatus strain. Bath. Arch. Microbiol., 114, 273-279.

Ehlers W., Köpke U., Hesse F., and Böhm W., 1983. Penetration resistance and root growth of oats in tilled and untilled loess soil. Soil Tillage Res., 3(3), 261-275.

Ehlers W., Werner D., and Mähner T., 2000. Wirkung mechanischer Belastung auf Gefüge und Ertragsleistung einer Löss-Parabraunerde mit zwei Bearbeitungssystemen. J. Plant Nutr. Soil Sci., 163, 321-333.

Fazekas O. and Horn R., 2005. Zusammenhang zwischen hydraulischer und mechanischer Bodenstabilität in Abhängigkeit von der Belastungsdauer. J. Plant Nutr. Soil Sci., $168,60-67$.

Hartge K. and Bohne H., 1983. Einfluß der Gefügegeometrie auf Verdichtbarkeit des Bodens und auf Keimung von Roggen. Z. f. Kulturtechnik und Flurbereinigung, 24, 11-18.

Hartge K.H. and Horn R., 2009. Die physikalische Untersuchung von Böden. Schweizerbart'sche Verlagsbuchhandlung.

Hartge K.H. and Horn R., 2014. Einführung in die Bodenphysik. Schweizerbart'sche Verlagsbuchhandlung, ISBN 978-3510-65288-4.

Horn R., 2004. Structure formation and its consequences on gas and water transport in unsaturated arable and forest soils. In: Soil-Plant-Atmosphere Aeration and Environmental Problems (Eds J. Gliński, G. Józefaciuk, K. Stahr), Lublin - Stuttgart.

Horn R., Domżał H., Słowińska-JurkiewiczA., and van Ouwerkerk C., 1995. Soil compaction processes and their effects on structure of arable soils and environment. Soil Till. Res., $35,23-36$
Horn R. and Fleige H., 2003. A method for assessing the impact of load on mechanical stability and on physical properties of soils. Soil Till. Res., 73, 89-99.

Horn R. and Smucker A., 2005. Structure formation and its consequences for gas and water transport in unsaturated arable and forest soils. Soil Till. Res., 82, 5-14.

Horn R., Taubner H., Wuttke M., and Baumgartl T., 1994. Soil physical properties related to soil structure. Soil Till Res., $30,187-216$.

Horn R., van den Akker J.J.H., and Arvidsson J., 2000. Subsoil compaction: Distribution, processes and consequences. Advances in GeoEcology, 32, Catena, Reiskirchen, $462 \mathrm{~S}$.

Jasińska E., Wetzel H., Baumgartl T., and Horn R., 2006. Heterogeneity of physico-chemical properties in structured soils and its consequences. Pedosphere, 16(3), 284-296.

King G.M. and Schnell S., 1994. Ammonium and nitrite inhibition of methane oxidation by Methylobacter albus BG8 and Methylosinus trichosporium OB3b at low methane concentrations. Appl. Environ. Microbiol., 60, 3508-3513.

Kuzyakov Y. and Blagodatskaya E., 2015. Microbial hotspots and hot moments in soil: Concept review. Soil Biol. Biochem., 83, 184-199.

Linn D.M. and Doran J.W., 1984. Effect of Water-Filled Pore Space on Carbon Dioxide and Nitrous Oxide Production in Tilled and Nontilled Soils. Soil Sci. Soc. Am. J., 48, 1267-1272.

Mancinelli R.L. and McKay C.P., 1985. Methane-oxidizing bacteria in sanitary landfills. In: First Int. Symposium Biotechnological Advances in Processing Municipal Wastes for Fuels and or Chemicals (Ed. A. Antonopoulos), $438-450$

McGill J., Tukey J.W., and Larsen W.A., 1978. Variations of box plots. The American Statistician, 32(1), 12-16.

Mer J.L. and Roger P., 2001. Production, oxidation, emission and consumption of methane by soils: A review. Eur. J. Soil Biol., 37, 25-50.

Mordhorst A., Peth S., and Horn R., 2014. Influence of mechanical loading on static and dynamic $\mathrm{CO}_{2}$ efflux on differently textured and managed Luvisols. Geoderma, 219-220, 1-13.

Nesbit S.P. and Breitenbeck G.A., 1992. A laboratory study of factors influencing methane uptake by soil. Agric. Ecosys. Environ., 41, 39-54.

Nichols K.A. and Halvorson J.J., 2013. Roles of biology, chemistry and physics in soil macroaggregate formation and stabilization. The Open Agr. J., 7, 107-117.

Pell M., Stenström J., and Granhall U., 2006. Soil respiration. In: Microbiological Methods for Assessing Soil Quality (Eds J. Bloem, D.W. Hopkins, A. Benedetti). Cab Intl.

Pengthamkeerati P., Motavalli P.P., and Kremer R.J., 2011. Soil microbial activity and functional diversity changed by compaction, poultry litter and cropping in a claypan soil. Appl. Soil Ecol., 48(1), 71-80.

Peth S., 2004. Bodenphysikalische Untersuchungen zur Trittbelastung von Böden bei der Rentierweidewirtschaft an borealen Wald und subarktisch-alpinen Tundrenstandorten.

Peth S., Rostek J., Zink A., Mordhorst A., and Horn R., 2010. Soil testing of dynamic deformation processes of arable soils. Soil Till. Res., 106(2), 317-328.

Powlson D.S., Goulding K.W.T., Willison T.W., Webster C.P., and Hutsch B.W., 1997. The effect of agriculture on methane oxidation in soil. Nutr. Cycl. in Agroecosys., 49, 59-70. 
R Core Team, 2014. R: A language and environment for statistical computing. R Foundation for Statistical Computing, Vienna, Austria. ISBN 3-900051-07-0, URL http://www.Rproject.org/

Schaarschmidt F. and Vaas L., 2009. Analysis of Trials with Complex Treatment Structure Using Multiple Contrast Tests, Hortscience, 44, 188-195.

Schlichting E., Blume H.-P., and Stahr K., 1995. Bodenkundliches Praktikum. Blackwell Wissenschafts-Verlag, Berlin, Wien.

Six J., Bossuyt H., Degryze S., and Denef K., 2004. A history of research on the link between (micro)aggregates, soil biota, and soil organic matter dynamics. Soil Till. Res., 79, 7-31

Suarez D.L. and Simunek J., 1993. Modelling of Carbon Dioxide Transport and Production in Soil 2. Parameter Selection, Sensitivity Analysis, and Comparison of Model Predictions to field Data. Water Resour. Res., 29(2), 499-513.

Stępniewski W., 2002. Oxygen diffusion rate and plant growth. In: Encyclopedia of Soil Science, Marcel-Dekker, Inc. ISBN: 082470634.

Stępniewski W. and Stępniewska Z., 2009. Selected oxygendependent process - Response to soil management and tillage. Soil Till. Res., 102, 193-200.
Verbeke G. and Molenberghs G., 2000. Linear Mixed Models for Longitudinal Data, Springer.

Watts C.W., Hallett P.D., and Dexter A.R., 1999. Effects of mechanical stresses and strains on soil respiration. In: The effect of mineralorganic microorganism interactions on soil and freshwater environments (Eds J. Berthelin et al.). Plenum Publ., New York.

Wiesmeier M., Steffens M., Mueller C.W., Kölbl A., Reszkowska A., Peth S., Horn R., and Kögel-Knabner I., 2012. Aggregate stability and physical protection of soil organic carbon in semi-arid steppe soils. Eur. J. Soil Sci., 63(1), 22-31.

Wrage N., Velthof G.L., Beusichem van M.L., and Oenema O., 2001. Role of nitrifier denitrification in the production of nitrous oxide, Soil Biol. Biochem., 33, 1723-1732.

WRB, 2006. World reference base for soil resources, FAO. ed, World Soil Resources Reports No. 103, Rome.

Zibilske L.M., 1994. Carbon mineralization. In: Methods of Soil Analysis. Part 2 (Eds J.M. Bigham et al.). SSSA Book Ser. 5. SSSA, Madison, WI, USA. 